\title{
Galantamine Facilitates Acquisition of a Trace-Conditioned Eyeblink Response in Healthy, Young Rabbits
}

\author{
Barbara B. Simon, ${ }^{1,2,4}$ Bryan Knuckley, ${ }^{1}$ and Donald A. Powell ${ }^{1,2,3}$ \\ ${ }^{1}$ Shirley L. Buchanan Neuroscience Laboratory, WJB Dorn VA Medical Center, Columbia, South Carolina 29209, USA; \\ ${ }^{2}$ Department of Psychology and ${ }^{3}$ Department of Neuropsychiatry and Behavioral Science, University of South Carolina School \\ of Medicine, Columbia, South Carolina 29208, USA
}

\begin{abstract}
Previous work has demonstrated that drugs increasing brain concentrations of acetylcholine can enhance cognition in aging and brain-damaged organisms. The present study assessed whether galantamine (GAL), an allosteric modulator of nicotinic cholinergic receptors and weak acetylcholinesterase inhibitor, could improve acquisition and retention of an eyeblink (EB) classical conditioning task in healthy, young animals. We trained 24 rabbits ( $n=8 /$ group) in a 1000-msec trace Pavlovian EB conditioning paradigm in which a tone conditioned stimulus (CS) was presented for $500 \mathrm{msec}$, followed by a 500-msec trace period in which no stimuli were presented. A 100-msec corneal airpuff was the unconditioned stimulus (US). Acquisition sessions, consisting of 100 trials each, occurred daily for 10 consecutive days, followed by $3 \mathrm{~d}$ of extinction training. Animals were treated with one of three doses of GAL $(0.0-3.0 \mathrm{mg} / \mathrm{kg})$ prior to each session. Animals that received $3.0 \mathrm{mg} / \mathrm{kg}$ GAL showed significantly more EB conditioned responses (CRs) in fewer training trials than animals receiving either $1.5 \mathrm{mg} / \mathrm{kg} \mathrm{GAL}$ or vehicle injections. GAL had no effect on CR performance during extinction. Pseudoconditioning control experiments, consisting of 200 explicitly unpaired tone-puff presentations indicated that GAL did not increase reactivity to the CS or US. These findings indicate that GAL may improve acquisition of moderately difficult associative learning tasks in healthy young organisms.
\end{abstract}

Galantamine (also galanthamine or Reminyl; Janssen) is an allosteric modulator of nicotinic acetylcholine receptors (nAChRs), known to improve cognitive function in impaired organisms (e.g., Fulton and Benfield 1996). Galantamine (GAL) functions both as a potentiating ligand and as a weak acetylcholinesterase (AchE) inhibitor. As a potentiating ligand, GAL facilitates Ach release by binding to presynaptic nAChRs and increasing the number of open postsynaptic receptors during action potentials. (Geerts et al. 2002). As an AchE inihibitor, GAL prevents the breakdown of Ach in cortical tissue (Sweeney et al. 1989; Geerts et al 2002). GAL has been found to significantly increase nicotinic receptor binding and decrease brain levels of AchE in rabbits (Woodruff-Pak et al. 2001). This compound also increased nicotinic receptor density in the hippocampus and prefrontal cortex in rats, leading to enhanced long-term potentiation of cells in these areas (Barnes et al. 2000). It is believed that this dual action of GAL, both facilitating Ach release and preventing the breakdown of Ach in the synapse, offers greater efficacy than other cholinergic agonists for longer treatment periods with less risk of tolerance in the treatment of cognitive dysfunction due to Alzheimer's disease (Maelicke 2001; Geerts et al. 2002; WoodruffPak et al. 2002).

Animal studies have shown that GAL can reverse the cognitive deficits caused by treatment with anticholinergic drugs (i.e., scopolamine or mecamylamine) and brain lesions (Fulton and Benfield 1996), as well as normal aging (Woodruff-Pak and Santos 2000; Woodruff-Pak et al. 2001). Certain kinds of Pavlovian EB conditioning tasks have proven to be a sensitive index of simple associative learning processes often disrupted in both ag-

\section{${ }^{4}$ Corresponding author.}

E-MAIL barbara.simon2@med.va.gov; FAX (803) 695-7942.

Article and publication are at http://www.learnmem.org/cgi/doi/10.1101/ Im.66204. ing organisms (e.g., Powell 1999) and various types of brain dysfunction including Alzheimer's disease (AD; Solomon et al. 1991, 1995; Woodruff-Pak and Papka 1996; Woodruff-Pak et al. 1996a,b), Korsakoff's disease (McGlinchey-Berroth et al. 1995), schizophrenia (Sears et al. 2000), and post-traumatic stress disorder (PTSD; Rasmusson and Charney 1997). Previous studies have demonstrated that treatment with $3.0 \mathrm{mg} / \mathrm{kg}$ GAL can significantly improve simple-delay eyeblink (EB) conditioning in older rabbits (Woodruff-Pak and Santos 2000; Woodruff-Pak et al. 2001).

Although simple-delay conditioning can be disrupted through aging and following certain types of brain damage (i.e., cerebellar damage, e.g., Thompson 2000), trace conditioning tasks, in which the CS and US are temporally distinct, are typically much more difficult to learn, even in young, healthy organisms. Thus the present experiment assessed the efficacy of GAL in healthy rabbits performing this difficult task to assess whether GAL might provide benefit in the treatment of learning or attention disorders in healthy, young organisms. Previous studies by Woodruff-Pak and colleagues (e.g., Woodruff-Pak and Santos 2000; Woodruff-Pak et al. 2001) found that $3.0 \mathrm{mg} / \mathrm{kg}$ GAL facilitated acquisition of simple-delay conditioning in both younger and aged animals, whereas lower $(1.0$ and $2.0 \mathrm{mg} / \mathrm{kg})$ and higher doses $(4.0 \mathrm{mg} / \mathrm{kg})$ did not. For example, WoodruffPak and Santos (2000) demonstrated highly significant decreases in the number of trials required to reach an EB learning criterion (eight EB conditioned responses within nine consecutive trials). Aged rabbits injected with $3.0 \mathrm{mg} / \mathrm{kg}$ GAL reached criterion in $233( \pm 176.9)$ trials, compared with an average of $1000( \pm 200$ 300 ) trials in untreated older animals. Studies from this lab have also shown that, whereas other compounds facilitating Ach transmission, including the $\alpha 7$ nicotinic partial agonist GTS-21 and the cholinesterase inhibitors donepezil and physostigmine, can significantly increase learning; treatment with GAL yielded 
even greater improvement. A second study further demonstrated that treatment with $3.0 \mathrm{mg} / \mathrm{kg}$ GAL facilitated learning a simple delay (750 msec) EB conditioned response (CR) in young (4-6 mo old) as well as older (15-43 mo old) rabbits (Woodruff-Pak et al. 2001).

These findings are especially compelling because younger organisms typically perform so well on this simple task that it is difficult to find significant facilitation because of ceiling effects. We therefore tested the optimal $3.0-\mathrm{mg} / \mathrm{kg}$ dose, as well as a lower $1.5-\mathrm{mg} / \mathrm{kg}$ dose, in younger animals performing a difficult EB trace-conditioning task, where such ceiling effects are not present. Evidence indicates that enhancement of cognitive function with pharmacological agents is dependent on task demands (e.g., Hahn et al. 2002), such that performance on simple tasks is typically not improved because of ceiling effects, whereas performance on difficult tasks may not be facilitated because organisms may not understand the task contingencies well enough to show improvement. The objective of the present study was thus to assess the effects of GAL on acquisition of the more difficult trace EB conditioning task, which requires higher cognitive demands (Clark and Squire 1998) to determine if this drug might be useful in the treatment of attentional dysfunction in humans.

\section{RESULTS}

A preliminary analysis of the pseudoconditioning control data indicated that $3.0 \mathrm{mg} / \mathrm{kg}$ GAL had no effect on either the unconditioned or conditioned responses. Mean EB CRs for all conditioning sessions was $10.6( \pm 1.4)$. However, a 2 (group) $\times 13$ (session) ANOVA on percentage EB responses per session indicated that EBs did significantly increase over sessions $\left(F_{(1,12)}=2.23\right.$, $p=0.022)$, although there was not a significant group effect $\left(F_{(1,12)}=0.01, p=0.935\right)$, nor was there a group-by-session interaction $\left(F_{(1,12)}=0.45, p=0.9344\right.$; see Fig. 1$)$. Because there were no significant group differences in this analysis, we conclude that GAL does not sensitize the animals to either the CS or US.

A two-way ANOVA using only the data from the experimental animals compared the effects of the three doses of GAL on percentage of CRs during acquisition. This analysis indicated significant main effects of group $\left(F_{(2,159)}=4.26, p<0.03\right)$ and session $\left(F_{(9,18)}=2.81, p<0.004\right)$; however, the interaction was not significant. Post hoc analyses revealed that $3.0 \mathrm{mg} / \mathrm{kg}$ GAL produced significantly greater percentages of CRs throughout training than either a lower dose of $1.5 \mathrm{mg} / \mathrm{kg}$ GAL or vehicle controls $(p<0.05)$. There was no significant difference between vehicle and the lower dose GAL group (difference of means over training $=0.81, p>0.05)$. Analyses of extinction data indicated that there was no significant difference in percentage of CRs between groups over extinction sessions $\left(F_{(8,51)}=\right.$ 1.15, $p>0.05$; see Fig. 1).

Additional planned comparisons between doses for each training day for the conditioning groups indicated significant group differences on acquisition days 1, 3, and $5\left(F_{(2,24)}=11.0,5.75\right.$, and 3.75 , respectively; all $p s<0.05$; see Fig. 1). Differences between the groups approached significance on training day 2 $\left(F_{(2,24)}=3.21, p=0.0599\right)$ and day $4\left(F_{(2,24)}=3.28, p=0.0567\right)$. Post hoc comparisons (Student-Newman-Keuls) indicated that treatment with $3.0 \mathrm{mg} / \mathrm{kg}$ GAL resulted in a significantly greater number of CRs than both $1.5 \mathrm{mg} / \mathrm{kg} \mathrm{GAL}$ and vehicle on conditioning days 1 and 3, and significantly more CRs than $1.5 \mathrm{mg} / \mathrm{kg}$ GAL on conditioning day 5 (again, see Fig. 1).

An interesting aspect of the data shown in Figure 1 is that the differences between the conditioning groups occur during the initial session. Thus acquisition for the $3-\mathrm{mg} / \mathrm{kg}$ group appears to be relatively complete during session 1 . To determine whether an acquisition function was apparent in this group, CR probability was assessed on a trial-by-trial basis as a function of the first 10 trials of session 1. These data are shown in Figure 2A. This figure indicates that, indeed, the actual acquisition of the $\mathrm{EB}$ CR occurs very rapidly during the first 10 trials of both drug groups, compared with the vehicle control group. In fact, as indicated in Figure 2B, which shows the mean number of EB CRs as a function of 10 trial blocks during session 1, acquisition in this latter group does not begin until late during this session, and as illustrated in Figure 1 remains well below that of the $3-\mathrm{mg} / \mathrm{kg}$ group throughout training. These data strongly indicate that the effects of GAL are on acquisition of the EB CR and not on possible nonspecific factors that may have increased reactivity to stimulation.

Analyses of EB CR amplitude data over training sessions (shown in Fig. 3A) indicated a significant main effect of session $\left(F_{(9,18)}=4.34, p<0.0001\right)$, but no significant group effect. Analysis of EB CR amplitude during extinction revealed no significant

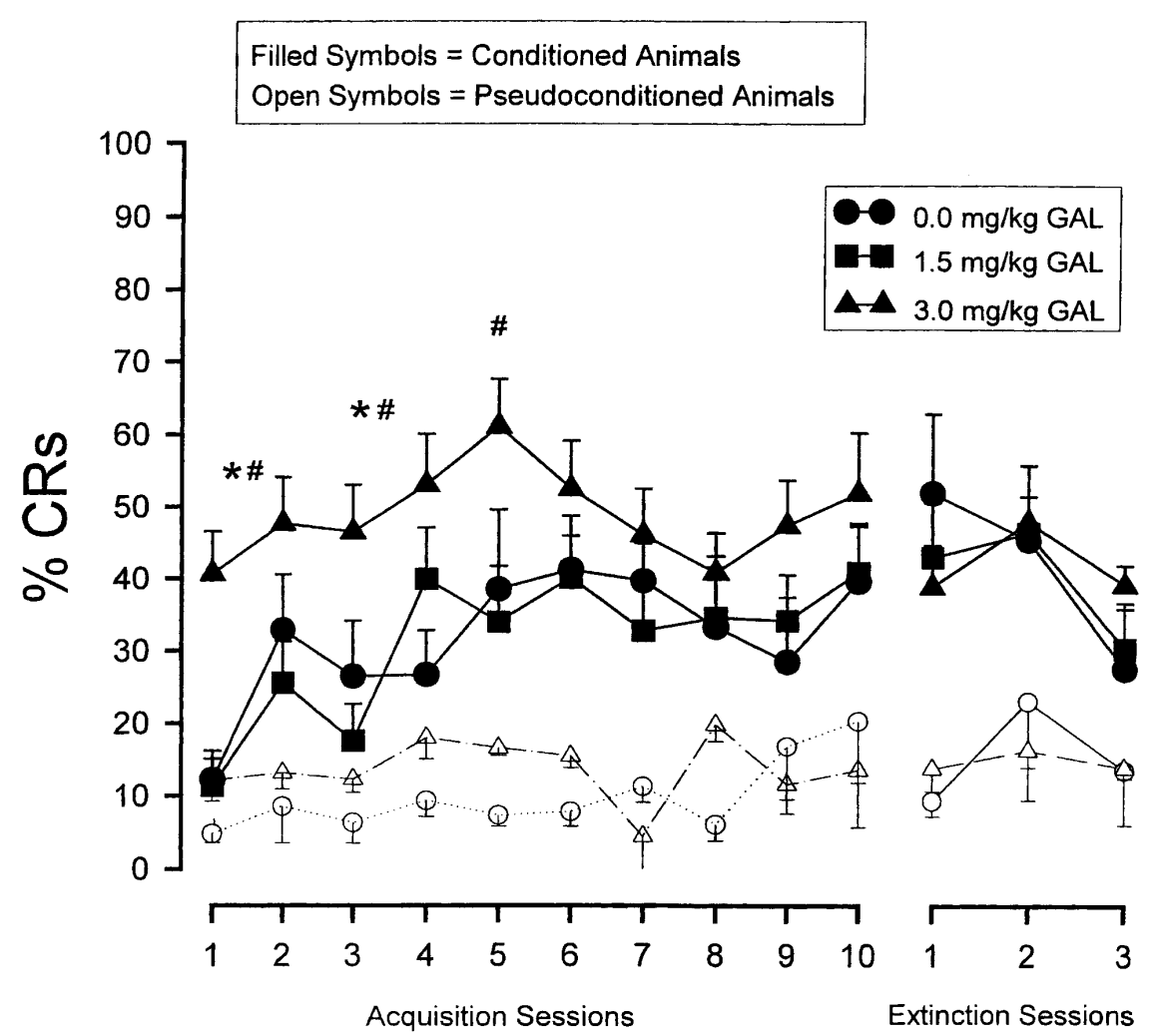

Figure 1 Effects of three doses of galanthamine (GAL; as indicated) on acquisition and extinction of conditioned eyeblink (EB) responses (CRs) in a trace-conditioning paradigm. The acquisition data represent the percent EB CRs during each 100-trial session during which a 500-msec, 1000$\mathrm{Hz}, 75-\mathrm{db}(\mathrm{SPL})$ tone-conditioned stimulus (CS) was presented $500 \mathrm{msec}$ prior to a $100-\mathrm{msec}, 3-\psi$ corneal airpuff unconditioned stimulus on each trial. During extinction, $100 \mathrm{CS}$-alone trials were presented. 

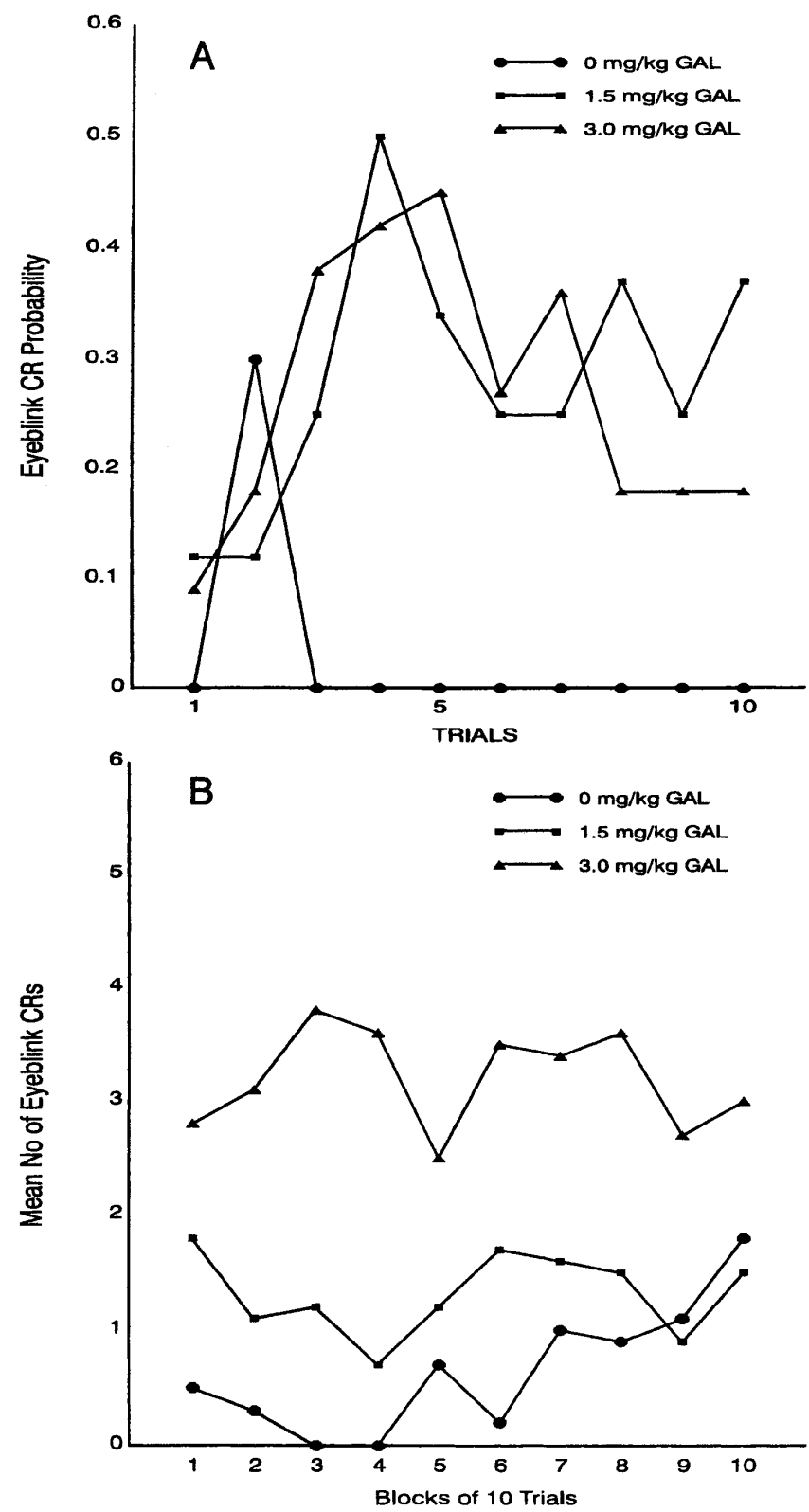

Figure 2 (A) Eyeblink conditioned response (EB CR) probability during the first 10 trials of session 1 for groups of rabbits that received different doses of galanthamine hydrobromide as shown. (B) Mean number of eyeblink conditioned responses (CRs) as a function of blocks of 10 trials each during the first session of trace classical conditioning. Data are shown for three groups of eight rabbits each that received different doses of galanthamine hydrobromide as shown.

effects (all ps > 0.05). Analysis of EB UR amplitude during conditioning and extinction also revealed no significant effects (all ps > 0.05).

Analysis of EB CR and UR latency data over training (shown in Fig. 3B) revealed that there were no changes in latency within or between groups over acquisition or extinction sessions for either CR or UR latencies (all $p s>0.05$ ).

Analysis of the amplitude and latency data for CRs and URs during the pseudoconditioning tests also indicated no significant differences between groups on either of these measures (all ps $>0.05$ ). These data are shown in Figure 4.

Because stimulant drugs like nicotine, which is another cho- linergic agonist, often have anorectic effects, animal weights were analyzed to assess the effects of GAL on weight gain over training and extinction sessions. Data from all experimental and control rabbits were analyzed together and can be seen in Figure 5. A 3 (group) $\times 13$ (training and extinction day) ANOVA indicated that weights significantly increased in all animals over sessions $\left(F_{(12,24)}=2.81, p<0.001\right)$, without a significant group-bysession interaction $\left(F_{(12,24)}=1.11, p=0.33\right)$. Thus, galantamine does not appear to exert significant anorectic effects.

\section{DISCUSSION}

The present results show that a $3-\mathrm{mg} / \mathrm{kg}$ dose of galanthamine hydrobromide increases the rate of acquisition of a trace EB conditioned response, whereas lower doses do not. These data are compatible with the previous experiments of Woodruff-Pak et al. (2001), which showed that a similar dosage of galanthamine facilitated acquisition of a delay EB conditioning task in rabbits. This finding was, however, obtained with a fairly long interstimulus interval (e.g., $750 \mathrm{msec}$ ), which also produces slower conditioning than the more optimal 400-msec ISI (Buchanan et al. 1997). It thus appears that galanthamine, which is a cholinesterase inhibitor, as well as an allosteric nictonic receptor agonist, facilitates EB conditioning under conditions that make learning more difficult.

These data are also compatible with the general hypothesis that central cholinergic systems play a large role in classical EB conditioning. It has been determined, for example, that central cholinergic blockade with scopolamine or atropine severely impairs acquisition of delay EB conditioning (e.g., Kazis et al. 1973). The role of acetylcholine in learning and memory has also been widely supported in a number of other behavioral paradigms (for a recent review, see, e.g., Sarter and Bruno 1997). It has been suggested that delay EB conditioning using optimal stimulus parameters is not dependent on the hippocampus and is learned without awareness of the stimulus contingencies, whereas successful trace conditioning requires hippocampal processing and is dependent on conscious awareness (Clark and Squire 1998). In support of this conclusion are findings from rabbits showing that although increases in hippocampal neuronal activity are elicited by both delay and trace conditioning (Berger and Thompson 1978; Weiss et al. 1996), hippocampal damage does not produce deficits in delay conditioning (Schmaltz and Theios 1972), but can dramatically impair trace conditioning (Moyer Jr. et al. 1990). Moreover, the findings by several investigators that humans with temporal lobe or diencephalic damage can learn a delay EB conditioning task but have difficulty learning a trace task provides further evidence for this conclusion (Gabrieli et al. 1995; McGlinchey-Berroth et al. 1997; Clark and Squire 1998).

These findings are especially important in the context of pharmacological interventions for Alzheimer's disease, because the loss of cholinergic function appears to be prevalent in this disorder, especially in the hippocampal region (Bartus et al. 1982; Coyle et al. 1983; Nordberg 1992). The dependence of declarative learning and memory on the hippocampus is also widely accepted (Clark and Squire 1998). Thus, the use of the trace eyeblink conditioning task is especially illuminating in this context, because it is also dependent on the hippocampus, as well as cholinergic function. Finally, EB conditioning is also impaired in patients with early Alzheimer's disease (Woodruff-Pak et al. 1990; Solomon et al. 1995; Woodruff-Pak 2001). The present results thus indicate that galantamine might be an especially good therapeutic agent for delaying the onset of the devastating learning and memory problems associated with Alzheimer's disease and mixed dementia (Alzheimer's disease with cerebrovascular disease), and has in fact been shown to be efficacious in this

\section{Learning \& Memory}

www.learnmem.org 
A

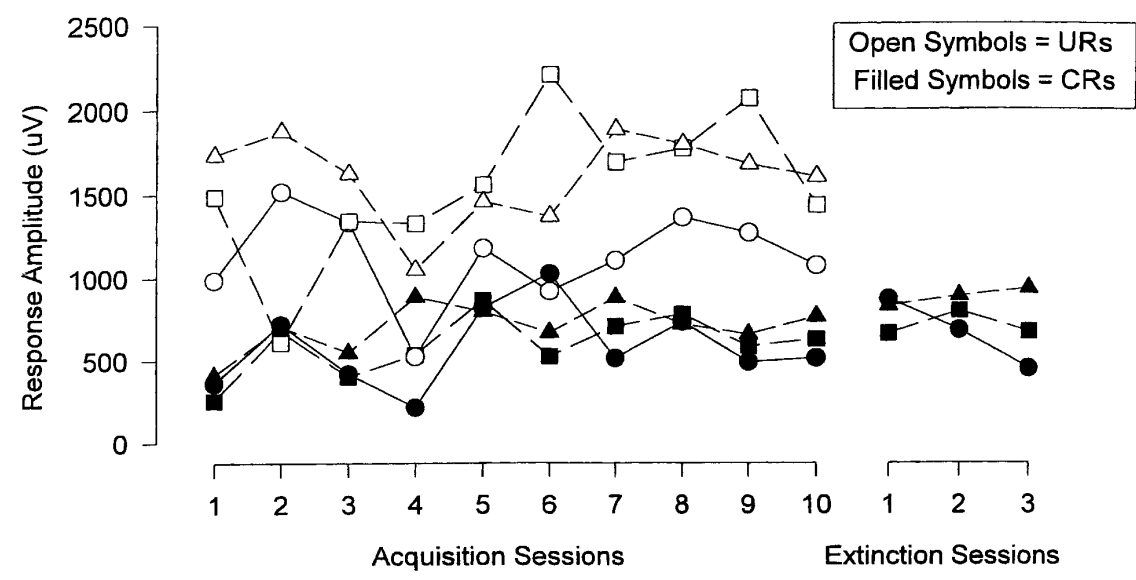

B

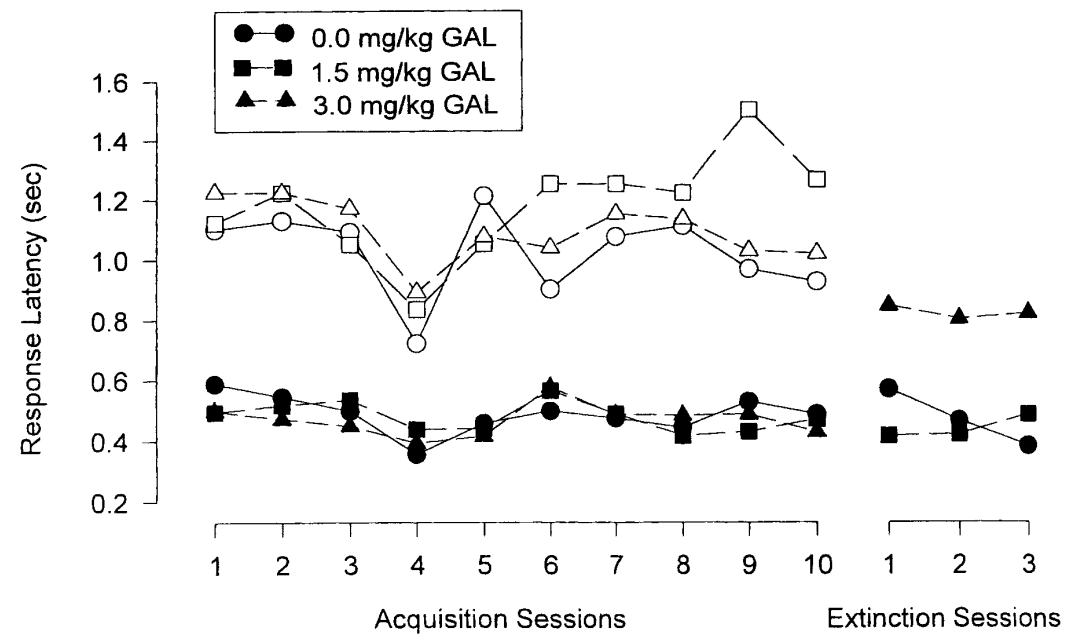

Figure 3 Effects of three doses of galanthamine (as indicated) on CR and UR amplitude $(A)$ and latency $(B)$ during trace eyeblink classical conditioning training and extinction. Each acquisition session consisted of $100 \mathrm{CS} /$ US presentations, and each extinction session consisted of $100 \mathrm{CS}$ presentations without the US occurring.

regard (e.g., Wilcock et al. 2000). These findings illustrate the efficacy of using EB conditioning tasks as a preclinical measure of associative learning and memory problems. Trace eyeblink conditioning in the rabbit thus appears to provide a valid animal model of the CNS dysfunctions that accompany the degenerative diseases of old age such as Alzheimer's or Parkinson's disease.

Another important aspect of the present results is that they indicate that treatment with GAL, and possibly other nonselective cholinergic agonists, may provide benefit for learning new, difficult material in young, healthy organisms. This is in contrast to traditional dopaminergic agonists, typically used in the treatment of attentional dysfunction in humans, which, while known to have benefit for aiding certain types of attentional focus in low doses (e.g., Grilly and Simon 1994), have been shown to have little benefit in improving acquisition of difficult tasks (Grilly et al. 1998) or even accuracy on tasks requiring certain forms of attention (e.g., Cole and Robbins 1987; Ljungberg and Enquist 1987; McGaughy and Sarter 1995). Thus, cholinergic agonists may prove more beneficial than dopaminergic agents for the treatment of attention-deficit/hyperactivity disorders. Indeed, work from several laboratories including Robbins and colleagues (e.g., Muir et al. 1992, 1994, 1995; for review, see Everitt and
Robbins 1997) and Sarter and colleagues (e.g., McGaughy et al. 1996) have long indicated that basal forebrain and other brain cholinergic systems are involved in attention, as lesions or chemical inactivation of cholinergic systems typically result in deficits on several animal models of attention including five-choice serial reaction time tasks (5-CSRTT; e.g., Robbins et al. 1989; McGaughy et al. 2002; Risbrough et al. 2002; Hahn et al. 2003a,b) and two-choice vigilance tasks (e.g., McGaughy and Sarter 1995; Turchi et al. 1995). Moreover, treatment with drugs that enhance Ach function such as physostigmine and nicotine can reverse the effects of lesions (e.g., Muir et al. 1995) or facilitate performance on tasks requiring sustained attention (e.g., Mizra and Stolerman 1998; Grilly et al. 2000). A more recent study further demonstrates the involvement of cortical Ach for tasks requiring sustained attention. Rats were trained in a two-choice operant task in which the correct lever was indicated by the position of a light; animals had to pay attention and "track" the position of the light to maximize water reinforcement. Microdialysis probes implanted in the frontoparietal cortex were used to asses Ach efflux during performance of the task. Results indicated significant increases in Ach levels that were directly related to the attentional requirements of the task, and were not the result of motor or motivational factors involved in task performance (Arnold et al. 2002).

Additional neuroanatomical evidence indicates that the attentional disruptions caused by decreases in cholinergic transmission are mediated at least in part by medial prefrontal cortex (mPFC; for a recent review, see Robbins 2002). Select lesions to mPFC by direct infusions of excitotoxins including quisolinic acid and $\alpha$-amino-2hydroxy-5-methyl-4-isoxazole proprionic acid (AMPA) disrupt attention as measured by decreased performance on the fivechoice serial reaction time task (Robbins 2002). In addition, excitotoxic lesions to the nucleus basalis magnollaris (nbm) result in decreased choline acetyltransferase (ChAT) activity, a cortical cholinergic marker, in rat PFC, likely owing to the lesion-induced disconnection between nbm and PFC (Robbins 2002). Peripheral (subcutaneous) administration as well as direct infusions of nicotine into PFC but not dorsal hippocampus improved accuracy on the 5-CSRTT in rats (Hahn et al. 2003). Thus, PFC appears to mediate at least certain forms of attention. This is especially relevant for the present study in which a trace EB conditioning task was used, a task also shown to be dependent on mPFC (Powell et al. 2000). Several studies from our laboratory have shown that both pre- and posttraining lesions to $\mathrm{MPFC}$ disrupt performance on a trace conditioning task in rabbits (e.g., Powell et al. 2001; McLaughlin et al. 2002), whereas mPFC lesions typically do not disrupt performance on simple-delay-conditioning tasks (Buchanan and Powell 1982). Trace conditioning tasks, therefore, appear to require attentional as well as other cognitive resources (e.g., working memory), as animals need to attend to the initially neutral CS, and then hold the memory for the CS through the 
A

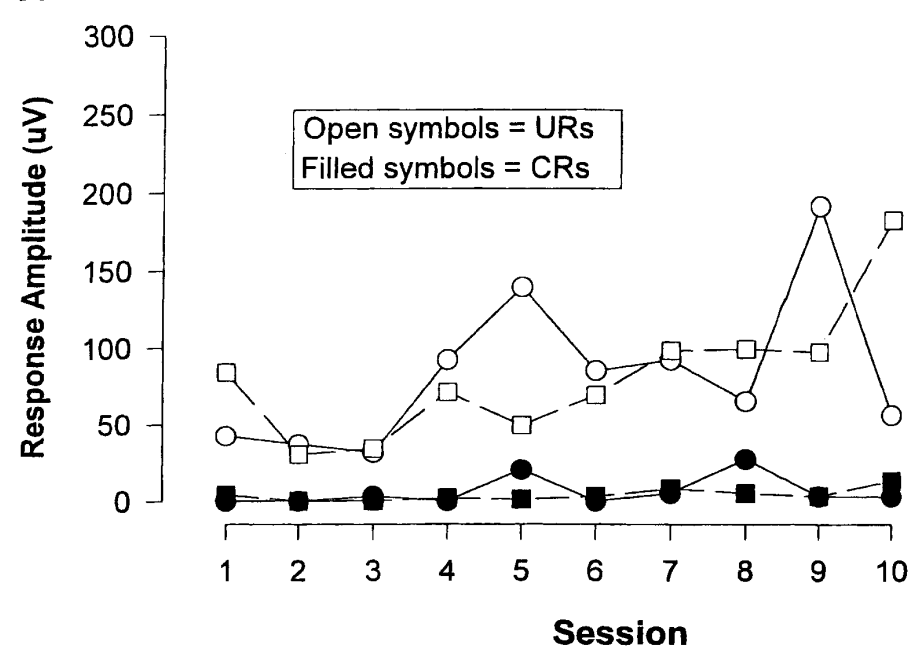

B

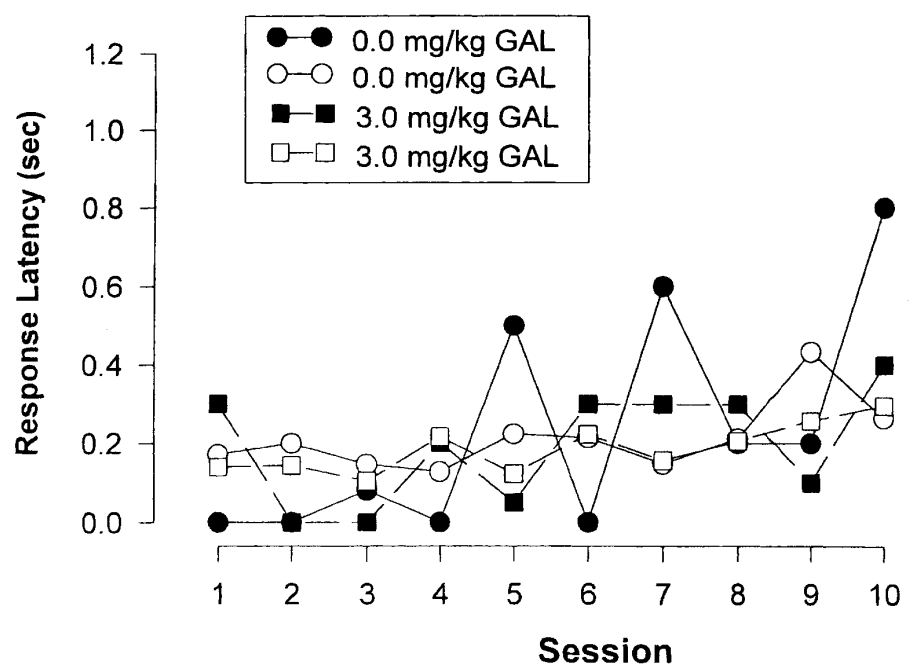

Figure 4 Effects of $3 \mathrm{mg} / \mathrm{kg}$ galanthamine or vehicle on eyeblink response amplitude and latency to unpaired tone and airpuffs presented in a pseudorandom sequence over $13 \mathrm{~d}$. (A) Effects of galantamine on CR amplitude during pseudoconditioning. (B) Effects of galantamine on CR latency during pseudoconditioning. A total of 100 presentations of each stimulus was presented on each day.

trace period so that the CS may be associated with the US. The present study indicates that increasing Ach transmission can facilitate performance on this difficult associative learning task in a manner similar to that observed for other tests of cognitive function including the 5-CSRTT and two-lever vigilance tasks. Thus, trace eyeblink conditioning in the rabbit may also provide a valid animal model of attention.

\section{MATERIALS AND METHODS}

\section{Subjects}

Animals were equal numbers of male and female New Zealand albino rabbits obtained from a USDA-licensed supplier (Robinson Services, Inc.) and maintained in an AAALAC-accredited animal facility. Food and water were freely available. All behavioral testing was conducted during the daylight portion of a 12:12 h light/ dark cycle with lights on at 7 a.m. All USPHS regulations regarding animal welfare were followed. There were eight animals in each of three dosage groups including $0 \mathrm{mg} / \mathrm{kg}, 1 \mathrm{mg} / \mathrm{kg}$, and 3 $\mathrm{mg} / \mathrm{kg}$ galanthamine hydrobromide. An additional 15 rabbits served as pseudoconditioning control animals. Seven of these animals received the vehicle alone, and eight received $3 \mathrm{mg} / \mathrm{kg}$ GAL.

\section{Drugs}

Galantamine hydrobromide $(4 a, 5,9,10,11$, 12-hexahydro-3-methoxy-11-methyl-6Hbenzofuro[3a,3,2-ef][2]benzazepin-6-ol hydrobromide) was purchased from Tocris Cookson Inc. or was generously donated by Janssen Pharmaceuticals. GAL was dissolved in sterile DI $\mathrm{H}_{2} \mathrm{O}$ in a solution of 1 $\mathrm{mg} / 0.25 \mathrm{~mL}$. Fresh solutions were prepared every $2-3 \mathrm{~d}$. All animals were weighed daily, and equal volumes of drug or vehicle according to animal weight were injected subcutaneously (sc) into the nape of the neck 30 min prior to conditioning sessions.

\section{Apparatus}

All experimental events (timing, delivery of stimuli, data collection, etc.) were controlled by microcomputer with user-written software, and interfaced with the animal chambers via TTL logic devices. Intertrial intervals (ITIs) were pseudorandomly programmed (range $=30-90 \mathrm{sec}$ ). All EB responses were recorded by the computer, and by a Grass Model 7 polygraph with appropriate preamplifiers.

During classical conditioning, the conditioned stimuli (CSs) were $1216-\mathrm{Hz}, 75$ 80-db (SPL) tones delivered for 500 msec. The unconditioned stimulus (US) was a puff of air to the cornea (3.0 psi) delivered for 100 msec. US onset began 500 msec after termination of the CS. The airpuff was carried to the eye via a plastic tube that was attached to a moveable wire arm mounted on slightly modified Gormezano-type Plexiglas rabbit restrainers (Gormezano 1966). The airpuff tube was attached to an air source through an electrically operated valve. The tube terminated on a $2-\mathrm{mm}$ diameter plastic pipette tip attached with Velcro to the moveable wire arm so that the pipette tip could be oriented for each animal $1 \mathrm{~cm}$ in front of the right orbit. Rabbit restrainers were placed inside sound- and light-deadened commercial chambers (Industrial Acoustics). Chambers were equipped with 6-in. overhead speakers placed $\sim 10$ in. above the animal's head, through which the computer-generated tone-conditioned stimuli were presented. The EB leads were connected to Grass EMG preamplifiers with integrators. Output of the driver amplifiers were input to the A-D card of the computer, where A-D recording was done in real time. The Grass polygraph also provided a permanent analog record of all data.

\section{Conditioning Procedures}

Prior to conditioning training, animals received three 1-h adaptation sessions to the experimental chamber, during which they were loosely restrained, but no stimuli were delivered. On day 3 of adaptation, all animals received vehicle injections $30 \mathrm{~min}$ prior to being placed in the testing chambers. Conditioning sessions and data collection began on day 4 . Training and test sessions consisted of 100 trials of CS-US pairings with an ITI of $60 \pm 30 \mathrm{sec}$. Sessions lasted $60 \mathrm{~min}$ and occurred once a day for $13 \mathrm{~d}$, which included $10 \mathrm{~d}$ of trace conditioning and $3 \mathrm{~d}$ of ex- 


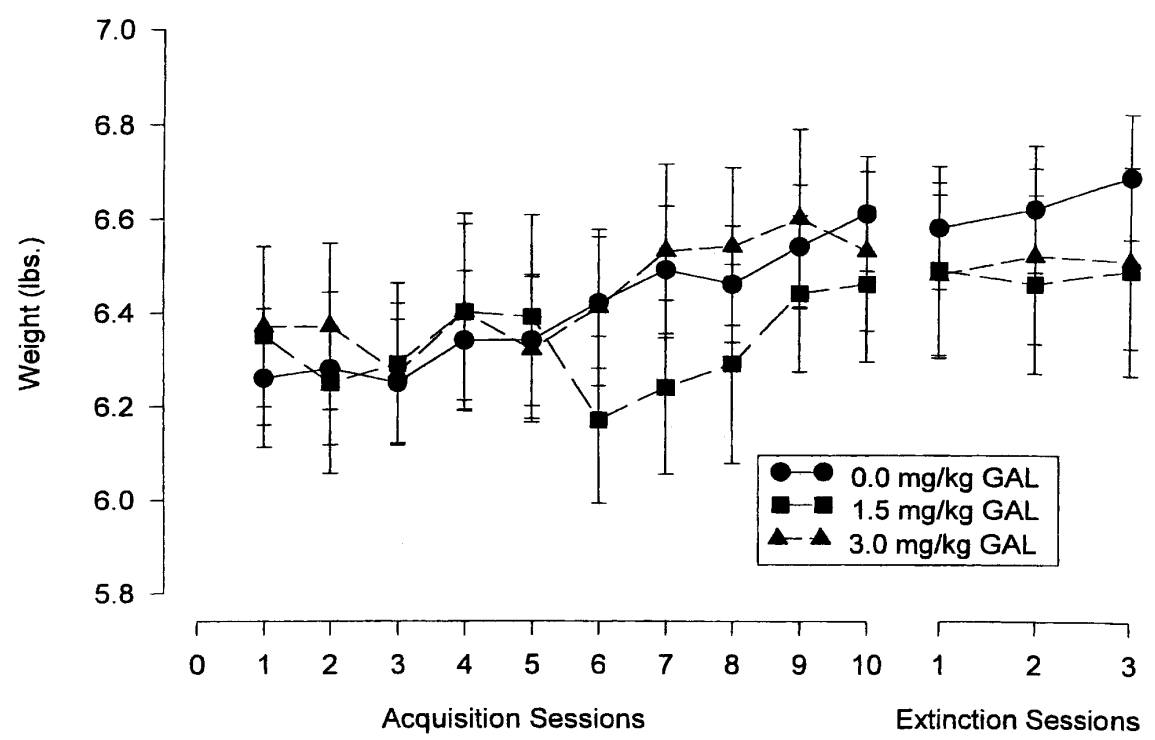

Figure 5 Effects of three doses of galanthamine (as indicated) on body weight over $13 \mathrm{~d}$ of training. Analyses indicated significant weight increases for all rabbits, with no significant group differences.

tinction training, consisting of 100 CS-alone trials with an ITI of $60 \pm 30$ sec.

Pseudoconditioning tests were conducted following either vehicle or $3.0 \mathrm{mg} / \mathrm{kg}$ GAL in 15 naive rabbits $(n=7$ in vehicle group, $n=8$ in $3.0 \mathrm{mg} / \mathrm{kg}$ GAL group) to ensure that increases in EB CRs observed during conditioning were not caused by nonassociative processes. Naive rabbits were habituated to the experimental situation as described above. Then, $30 \mathrm{~min}$ prior to pseudoconditioning sessions, animals were injected with either 3.0 $\mathrm{mg} / \mathrm{kg} \mathrm{GAL}$ or sterile DI $\mathrm{H}_{2} \mathrm{O}$. Each daily session consisted of 200 trials, $100 \mathrm{CS}$-alone trials and 100 US-alone trials, with an ITI $=30 \pm 15 \mathrm{sec}$ presented in a pseudorandom order such that neither stimulus was presented more than three consecutive times. Sessions lasted $60 \mathrm{~min}$ and occurred for $13 \mathrm{~d}$.

For recording the EB response, electrodes constructed of orthodontic wire were acutely inserted beneath the upper and lower eyelids. These electrodes allowed for simultaneous recording of eyelid closure and nictitating membrane extension (VanDercar et al. 1969). Electrodes were connected to a Grass model 7P3 preamplifier and integrator set in its integrator mode. The preamplifier was calibrated such that a $100-\mu \mathrm{V}$ change across the electrodes corresponded to a 1-mm deflection of the oscillograph pen. The amplitude of the signal (integrated over the CS interval) served as the EB measure. An EB CR was defined as a potential change of $100 \mu \mathrm{V}$ or greater, corresponding to $\sim 0.5 \mathrm{~mm}$ of eyelid movement. EB latency was defined as the time interval from CS onset until the CR exceeded $100 \mu \mathrm{V}$.

\section{Data Analysis}

Data on percent CRs were analyzed by two-way (group $\times$ session) mixed ANOVAs with group as a nonrepeated measure and session as a repeated measure. Training and extinction sessions were analyzed separately, and included all experimental and pseudoconditioning control animals $(n=39)$. Additional separate two-way ANOVAs compared percent CRs for experimental animals $(n=24)$ and control animals $(n=15)$ to assess dose effects. Additional separate one-way ANOVAs analyzed dose differences for each training or extinction day. Post hoc analyses used the Student-Newman-Keuls method to analyze group differences when the ANOVAs were significant. Separate three-way ANOVAs (group $\times$ session $\times$ trial) were used to analyze CR amplitude and CR latency data for all animals. Extinction and pseudoconditioning sessions counted CRs as any $100-\mu \mathrm{V}$ change across the electrode for $1 \mathrm{sec}$ following the onset of the CS tone.

\section{ACKNOWLEDGMENTS}

This research was supported by DVA General Medical Research funds awarded to the William Jennings Bryan Dorn VA Medical Center, Columbia, SC. The authors thank Elizabeth Hamel for assistance with manuscript preparation and Janssen Pharmaceuticals (Beerse, Belgium) for their generous donation of galanthamine hydrobromide.

The publication costs of this article were defrayed in part by payment of page charges. This article must therefore be hereby marked "advertisement" in accordance with 18 USC section 1734 solely to indicate this fact.

\section{REFERENCES}

Arnold, H.M., Burk, J.A., Hodgson, E.M., Sarter, M., and Bruno, J.P. 2002. Differential cortical acetylcholine release in rats performing a sustained attention task versus behavioral control tasks that do not explicitly tax attention. Neuroscience 114: 451-460.

Barnes, C.A., Meltzer, J., Houston, F., Orr, G., McGann, K., and Wenk, G.L. 2000. Chronic treatment of old rats with donepezil or galantamine: Effects on memory, hippocampal plasticity and nicotinic receptors. Neuroscience 99: 17-23.

Bartus, R.T., Reinald III, L.D., Beer, B., and Lippan, A.S. 1982. The cholinergic hypothesis of geriatric memory dysfunction. Science 217: 408-417.

Berger, T.W. and Thompson, R.F. 1978. Identification of pyramidal cells as the critical elements in hippocampal neuronal plasticity during learning. Proc. Natl. Acad. Sci. 75: 1572-1576.

Buchanan, S.L. and Powell, D.A. 1982. Cingulate cortex: Its role in Pavlovian conditioning. J. Compar. Physiol. Psych. 96: 755-774.

Buchanan, S.L., Penney, J., Tebbutt, D., and Powell, D.A. 1997. Lesions of the mediodorsal nucleus of the thalamus and classical eyeblink conditioning under less-than-optimal stimulus conditions: Role of partial reinforcement and interstimulus interval. Behav. Neurosci. 111: $1075-1085$.

Clark, R.E. and Squire, L.R. 1998. Classical conditioning and brain systems: The role of awareness. Science 280: 77-81.

Cole, B.J. and Robbins, T.W. 1987. Amphetamine impairs the discrimination performance of rats with dorsal bundle lesions on a 5-choice serial reaction time task: New evidence for central dopaminergic-noradrenergic interactions. Psychopharmacology 91: $458-466$.

Coyle, J.T., Price, D.L., and Delong, M.R. 1983. Alzheimer's disease: A disorder of cortical cholinergic innervation. Science 219: 1184-1190.

Everitt, B.J. and Robbins, T.W. 1997. Central cholinergic systems and cognition. Annu. Rev. Psych. 48: 649-684.

Fulton, B. and Benfield, P. 1996. Galanthamine. Drugs and Aging 9: $60-67$.

Gabrieli, J.D.E., McGlinchey-Berroth, R., Carrillo, M.C., Gluck, M.A., Cermak, L.S., and Disterhoft, J.F. 1995. Intact delay-eyeblink classical conditioning in amnesia. Behav. Neurosci. 109: 819-827.

Geerts, H., Finkel, L., Carr, R., and Spiros, A. 2002. Nicotinic receptor modulation: Advantages for successful Alzheimer's disease therapy. $J$ Neural Transmission Supplement 62: 203-216.

Gormezano, I. 1966. Classical conditioning. In Experimental methods and instrumentation in psychology (ed. J.B. Sidowski), pp. 385-420. McGraw Hill, New York.

Grilly, D.M. and Simon, B.B. 1994. Differential effects of $d$-amphetamine on vigilance in younger and older male rats. Pharmacol. Biochem. Behav. 49: 497-502.

Grilly, D.M., Pistell, P.J., and Simon, B.B. 1998. Facilitation of stimulus detection performance of rats with $d$-amphetamine: A function of dose and level of training. Psychopharmacology (Berl). 140: 272-278.

Grilly, D.M., Simon, B.B., and Levin, E.D. 2000. Nicotine enhances stimulus detection performance of middle- and old-aged rats: A longitudinal study. Pharmacol. Biochem. Behav. 65: 665-670.

Hahn, B., Shoaib, M., and Stolerman, I.P. 2002. Nicotine-induced enhancement of attention in the five-choice serial reaction time task: The influence of task demands. Psychopharmacology 162: $129-137$.

Hahn, B., Sharples, C.G.V., Wonnacott, S., Shoaib, M., and Stolerman, 
I.P. 2003a. Attentional effects of nicotinic agonists in rats. Neuropharmacology 44: 1054-1067.

Hahn, B., Shoaib, M., and Stolerman, I.P. 2003b. Involvement of the prefrontal cortex but not the dorsal hippocampus in the attention-enhancing effects of nicotine in rats. Psychopharmacology (April 16 online) 10.1007/s00213-003-1438-6.

Kazis, E., Milligan, W.L., and Powell, D.A. 1973. Autonomic-somatic relationships: Blockade of heart rate and corneoretinal potential. $J$. Compar. Physiol. Psych. 84: 98-110.

Ljungberg, T. and Enquist, M. 1987. Disruptive effects of low doses of $d$-amphetamine on the ability of rats to organize behaviour into functional sequences. Psychopharmacology 93: 146-151.

Maelicke, A. 2001. Allosteric modulation of nicotinic receptors as a treatment strategy for Alzheimer's disease. Dementia Ger. Cogn. Disorders 11 Suppl. 1: 11-18.

McGaughy, J.L. and Sarter, M. 1995. Behavioral vigilance in rats: Task validation and effects of age, amphetamine, and benzodiazepine receptor ligands. Psychopharmacology 117: 340-357.

McGaughy, J.L., Kaiser, T., and Sarter, M. 1996. Behavioral vigilance following infusions of $192 \mathrm{IgG}$-saporin into the basal forebrain: Selectivity of the behavioral impairment and relation to cortical AchE-positive fiber density. Behav. Neurosci. 2: 247-265.

McGaughy, J.L., Dalley, J.W., Morrison, C.H., Everitt, B.J., and Robbins, T.W. 2002. Selective behavioral and neurochemical effects of cholinergic lesions produced by intrabasalis infusion of 192 IgG-saporin on attentional performance in a five-choice serial reaction time task. J. Neurosci. 22: 1905-1913.

McGlinchey-Berroth, R., Cermak, L.S., Carrillo, M.C., Armfield, S Gabrieli, J.D., and Disterhoft, J.D. 1995. Impaired delay eyeblink conditioning in amnesic Korsakoff's patients and recovered alcoholics. Alcohol Clinical Exp. Res. 19: 1127-1132.

McGlinchey-Berroth, R., Carrillo, M.C., Gabrieli, J.D.E., Brawn, C.M. and Disterhoft, J.F. 1997. Intact delay-eyeblink classical conditioning in amnesia. Behav. Neurosci. 111: 873-882.

McLaughlin, J., Skaggs, H., Churchwell, J., and Powell, D.A. 2002 Medial prefrontal cortex and Pavlovian conditioning: Trace versus delay conditioning. Behav. Neurosci. 116: 37-47.

Mizra, N. and Stolerman, I.P. 1998. Nicotine enhances sustained attention in the rat under specific task conditions. Psychopharmacology 138: 266-274.

Moyer Jr., J.R., Deyo, R.A., and Disterhoft, J.F. 1990. Hippocampectomy disrupts trace eye-blink conditioning in rabbits. Behav. Neurosci. 104: $243-252$

Muir, J.L., Dunnett, S.B., Robbins, T.W., and Everitt, B.J. 1992. Attentional functions of the forebrain cholinergic system: Effects of intraventricular hemicholinium, physostigmine, basal forebrain lesions, and intracortical grafts on a multiple choice serial reaction time task. Exp. Brain Res. 89: 611-622.

Muir, J.L., Everitt, B.J., and Robbins, T.W. 1994. AMPA-induced lesions of the basal forebrain: A significant role of the cortical cholinergic system in attentional function. J. Neurosci. 14: 2313-2326. 1995. Reversal of visual attentional dysfunction following lesions of the cholinergic basal forebrain by physostigmine and nicotine but not the 5-HT3 receptor antagonist, ondansetron. Psychopharmacology 118: 82-92.

Nordberg, A. 1992. Biological markers and the cholinergic hypothesis in Alzheimer's disease. Acta Neurol. Scandinavica 139: $54-58$.

Powell, D.A. 1999. A behavioral stages model of classical (Pavlovian) conditioning: Application to cognitive aging. Neurosci. Biobehav. Rev. 23: $797-816$

Powell, D.A., McLaughlin, J., and Chachich, M. 2000. Classical conditioning of autonomic and somatomotor responses and their central nervous system substrates. In Eyeblink classical conditioning. Volume 2: Animal models (eds. J.E. Steinmetz, and D.S. Woodruff-Pak), pp. 257-286. Kluwer Academic Publishers, Boston.

Powell, D.A., Skaggs, H., Churchwell, J., and McLaughlin, J. 2001 Posttraining lesions of the medial prefrontal cortex impair performance of Pavlovian conditioned eyeblink performance but have no effect on concomitant heart rate changes. Behav. Neurosci. 115: $1029-1038$.

Rasmusson, A.N. and Charney, D.S. 1997. Animal models of relevance to PTSD. Ann. NY Acad. Sci. 821: 332-351.

Risbrough, V., Bontempi, B., and Menzaghi, F. 2002. Selective immunolesioning of the basal forebrain cholinergic neurons in rats:
Effect on attention using the 5-choice serial reaction time task. Psychopharmacology 164: 71-81.

Robbins, T.W. 2002. The 5-choice serial reaction time task: Behavioral pharmacology and functional neurochemistry. Psychopharmacology 163: $362-380$.

Robbins, T.W., Everitt, B.J., Martson, H.M., Wilkinson, J., Jones, G.H., and Page, K.J. 1989. Comparative effects of ibotinic acid- and quisqualic acid-induced lesions of the substantia innominata on attentional function in the rat: Further implications for the role of the cholinergic neurons of the nucleus basalis in cognitive processes. Behav. Brain Res. 35: 221-240.

Sarter, M. and Bruno, J.P. 1997. Cognitive function of cortical acetylcholine: Toward a unifying hypothesis. Brain Res. Rev. 23: $28-46$.

Schmaltz, L.W. and Theios, J. 1972. Acquisition and extinction of a classically conditioned response in hippocampectomized rabbits (Oryctolagus cuniculus). I. Compar. Physiol. Psych. 79: 328-333.

Sears, L.L., Andreasen, N.C., and O'Leary, D.S. 2000. Cerebellar functional abnormalities in schizophrenia are suggested by classical eyeblink conditioning. Biol. Psychiatry 48: 204-209.

Solomon, P.R., Levine, E., Bein, T., and Pendlebury, W.W. 1991. Disruption of classical conditioning in patients with Alzheimer's disease. Neurobiol. Aging 12: 283-287.

Solomon, P.R., Brett, M., Groccia-Ellison, M.G., Oyler, C., Tomasi, M., and Pendlebury, W.W. 1995. Classical conditioning in patients with Alzheimer's disease: A multiday study. Psych. Aging 10: 248-254.

Sweeney, J.E., Puttfarcken, P.S., and Coyle, J.T. 1989. Galanthamine, an acetylcholinesterase inhibitor: A time course of the effects on performance and neurochemical parameters in mice. Pharmacol. Biochem. Behav. 34: 129-137.

Thompson, R.F. 2000. Discovering the brain substrates of eyeblink classical conditioning. In Eyeblink classical conditioning. Volume 2: Animal models (eds. J.E. Steinmetz and D.S. Woodruff-Pak), pp. 17-49. Kluwer Academic Publishers, Boston.

Turchi, J., Holley, L.A., and Sarter, M. 1995. Effects of nicotinic acetylcholine receptor ligands on behavioral vigilance in rats. Psychopharmacology 118: 195-205.

VanDercar, D.H., Swadlow, H.A., Elster, A., and Schneiderman, N. 1969. Nictitating membrane and corneo-retinal transducers for conditioning in rabbits. Am. Psych. 24: 262-264.

Weiss, C., Kronforst-Collins, M.A., and Disterhoft, J.F. 1996. Activity of hippocampal pyramidal neurons during trace eyeblink conditioning. Hippocampus 6: 192-209.

Wilcock, G.K., Lilienfeld, S., and Gaens, E. 2000. Efficacy and safety of galantamine in patients with mild to moderate Alzheimer's disease: Multicentre randomized controlled trial. Br. Med. J. 321: 1445-1449.

Woodruff-Pak, D.S. 2001. Eyeblink classical conditioning differentiates normal aging from Alzheimer's disease. Integrative Phys. Behav. Sci. 36: $87-108$.

Woodruff-Pak, D.S. and Papka, M. 1996. Alzheimer's disease and eyeblink conditioning: $750 \mathrm{~ms}$ trace vs. $400 \mathrm{~ms}$ delay paradigm. Neurobiol. Aging 17: 397-404.

Woodruff-Pak, D.S. and Santos, I.S. 2000. Nicotinic modulation in an animal model of a form of associative learning impaired in Alzheimer's disease. Behav. Brain Res. 113: 11-19.

Woodruff-Pak, D.S., Finkbiner, R.G., and Sasse, D.K. 1990. Eyeblink conditioning discriminates Alzheimer's patients from non-demented aged. NeuroReport 1: 45-49.

Woodruff-Pak, D.S., Papka, M., Romano, S., and Li, Y.-T. 1996a. Eyeblink classical conditioning in Alzheimer's disease and cerebrovascular dementia. Neurobiol. Aging 17: 505-512.

Woodruff-Pak, D.S., Romano, S., and Papka, M. 1996b. Training to criterion in eyeblink classical conditioning in Alzheimer's disease, Down's syndrome with Alzheimer's disease, and healthy elderly. Behav. Neurosci. 110: 22-29.

Woodruff-Pak, D.S., Vogel III, R.W., and Wenk, G.L. 2001. Galantamine: Effect on nicotinic receptor binding, acetylcholinesterase inhibition, and learning. Proc. Natl. Acad. Sci. 98: 2089-2094.

Woodruff-Pak, D.S., Lander, C., and Geerts, H. 2002. Nicotinic cholinergic modulation: Galantamine as a prototype. CNS Drug Review 8: 405-426.

Received July 9, 2003; accepted in revised form November 24, 2003. 


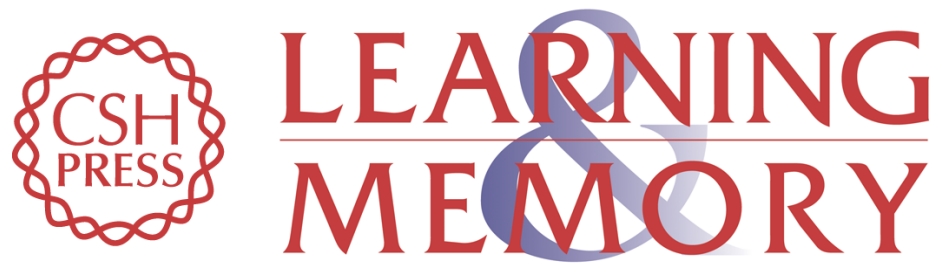

\section{Galantamine Facilitates Acquisition of a Trace-Conditioned Eyeblink Response in Healthy, Young Rabbits}

Barbara B. Simon, Bryan Knuckley and Donald A. Powell

Learn. Mem. 2004, 11:

Access the most recent version at doi:10.1101/lm.66204

References This article cites 52 articles, 8 of which can be accessed free at: http://learnmem.cshlp.org/content/11/1/116.full.html\#ref-list-1

License

Email Alerting

Receive free email alerts when new articles cite this article - sign up in the box at the Service top right corner of the article or click here. 